Thorax (1969), 24, 43.

\title{
Bronchial carcinoid tumours
}

\author{
R . A B B E Y S M I T H \\ From the Thoracic Surgical Unit, King Edward VII Chest Hospital, Hertford Hill, near Warwick
}

\begin{abstract}
Some features of 22 cases of carcinoid tumour are described. The histology of the tumour was the criterion for inclusion in the series. The histology was reviewed by an observer unfamiliar with the clinical features. Six patients, each with an entirely endobronchial tumour of typical histology treated satisfactorily by surgery, are excluded from further consideration ; the remaining 16 are considered for factors which may be significant in assessing the long-term prognosis, in addition to a histological assessment. The experience in this series is compared with a number of considerably larger series from the literature. The conclusion is reached that no single feature, histological or clinical, can be a basis for reaching a reliable prognosis. Lobectomy is regarded as the operation of choice in treatment.
\end{abstract}

From a personal series of 31 benign tumours of the lung and bronchus, 22 have been classified as carcinoid adenoma of the bronchus. A number of observations from experience gained on these carcinoid tumours will be presented. It is clear from a study of the literature on this tumour that opinion is not uniform on the subject. Different observers hold different opinions on the exact nature of the tumour and on its potential malignancy. d'Abreu (1958), in discussing the exceptional patient with a tumour showing invasive tendencies, involvement of local lymph nodes or distant deposits in the liver, stated 'on the grounds of these exceptional patients it hardly seems fair to incriminate the larger group as carcinoma, as this assumption would suggest that all these should be subjected to radical pneumonectomy'. What one group of observers would regard as a carcinoid tumour a second might describe by another name, implying a different prognosis.

The reason for the difference may be histological interpretation or the gross appearance of the tumour. Willis (1960) stated 'the prevalent opinion that adenoma is sharply distinct from carcinoma, is unjustified. I have seen two large tumours which histologically could be called either very active atypical adenomas or adenoma-like carcinomas'. On the gross appearance some would regard a tumour that has penetrated the bronchial wall as an 'iceberg' adenoma ; others would regard this as a carcinoma in spite of its histology. These considerations are real difficulties in discussing the problem of the carcinoid tumour. An equally important difficulty in reaching a firm conclusion on the behaviour of the carcinoid tumour is its long natural history-33 years in a patient described by Borggreve (1966) and $22 \frac{1}{2}$ years after endoscopic biopsy in a patient reported by Markel, Abell, Haight, and French (1964). Neither of these patients had any definitive therapy. Such a long natural history suggests that a follow-up period after operation of 10 years or so is relatively valueless.

Furthermore, the tumour is of such rarity that individual experience diminishes as the number of surgical centres treating the condition increases (Thompson, 1965). It is unlikely that the large series-111 described by McBurney, Kirklin, and Woolner (1953), 86 by Moersch and McDonald (1950), 82 by Wilkins, Darling, Soutter, and Sniffen (1963), 61 by Markel et al. (1964), 57 by Price Thomas (1954), and 56 by Baldwin and Grimes (1967) — will be repeated.

In spite of these difficulties, it is certain that more knowledge of every aspect of this tumour is necessary before its recognition and correct treatment can be placed on a logical basis.

\section{CRITERIA FOR ACCEPTANCE OF PATIENT TO THE SER!ES}

Acceptance has been exclusively on the histological appearance of the tumour in the surgical specimen or at necropsy. Any patient with biopsy material only has been excluded, except for one (patient 15, Table). Each tumour has shown the general histological characteristics of the bronchial carcinoid, including those in which the pathologist's report on the microscopy of the tumour 
suggested that it may have had malignant potential. Endobronchial tumours and those penetrating the bronchial wall have been included, as have those with lymph node deposits locally, provided the histological pattern was acceptable. The so-called peripheral carcinoids were excluded. No patient, once admitted, was excluded because the subsequent course was that of a frankly carcinomatous lesion, and no patient was brought into the series because subsequent long survival after operation suggested an alternative diagnosis. In other words, the original histological diagnosis reached after a full examination of the surgical specimen was firmly accepted. To include or exclude retrospectively would significantly change the mortality figures.

\section{REASONS FOR AND METHODS OF STUDY}

This study was undertaken primarily to investigate factors which might govern the prognosis in a patient with the histological diagnosis of carcinoid tumour of the bronchus. The view we originally held was that the degree of penetration of the bronchial wall by the tumour was of more importance in confirming potential malignancy than the histological appearance, a similar view, in fact, to that now taken of malignant thymic tumours in which penetration of the thymic capsule is regarded as a more reliable index of malignancy than is the histological appearance (Edmunds, 1966).

In each patient with a carcinoid tumour, longterm survival after operation was assumed to depend on the malignant potential of the tumour. An attempt was made to correlate, independently of the histology, potential malignancy with a number of factors to be discussed. In addition, in 1967 (some 15 years after the start of the period of observation) the pathology of the tumours was reviewed by a pathologist who had no clinical details available and no knowledge of the patients' follow-up. Two separate pathological opinions on each specimen were therefore available, one by a pathologist at the time of the original operation who had the full clinical details available and who examined every tumour, the other from a different pathologist who gave an opinion solely on the histology of the available slides of each tumour. This method, although unfair to the pathologist, seemed one by which an assessment of the importance of the histology might be made. Its shortcomings were apparent, one being that although the histological appearance was the criterion for admission of a patient to the series, its importance was in part denied in assessing the $\stackrel{\vec{F}}{\vec{P}}$ ultimate outcome.

\section{DETAILS OF CASES AND RESUlts (TABLE)}

In six patients the tumour was a typical wholly endobronchial carcinoid and the results of surgical treatment were satisfactory. These will not be considered further. The details of the remaining $16 \overrightarrow{\vec{\omega}}$ patients are presented. The most striking feature ${ }^{\circ}$ was the death rate directly attributable to exten- $\overrightarrow{\vec{x}}$ sion of the disease-five of 16 patients. This is a i higher figure than that recorded by other authors. Markel et al. (1964) reported three deaths in $53 \vec{s}$ patients with tumours attributable to extension. Wilkins et al. (1963) record five attributable deaths out of 64 survivors from 67 resections ; two $\vec{c}$ of these deaths, however, were in patients with cylindromas. The death rate due to recurrence will depend, among other factors, on the original histological criteria, on whether there has been $\vec{\varphi}$ retrospective exclusion of cases because progress 8 was that of a carcinoma, and on the availability of necropsy material after the patient's death. The recurrence of the disease in patient 10 , eight years after local removal, was entirely symptomless and detected only by routine bronchoscopy because of $\frac{\varnothing}{\varnothing}$ a radiological change. It is clear, therefore, that $\varrho$ recurrence may be symptomless and it is well $\overrightarrow{\overrightarrow{0}}$ known that recurrence may be associated with 3 survival for many years.

It is doubtful if such an extensive resection as pneumonectomy has any virtue if technically a lesser operation is possible, using, for instance, the technique of sleeve resection with end-to-end $\times$ bronchial anastomosis described by Price Thomas (1956). On the other hand, we no longer use local removal by bronchoscopy or at thoracotomy by bronchotomy. Of three patients treated by thoracotomy and local excision of the tumour? through an incision of the bronchial wall, one $\frac{}{0}$ (case 10) recurred and one later required resection for irreversible bronchiectasis. The presence ${ }_{\mathcal{O}}$ of irreversible bronchiectasis may be difficult to establish at the time the local resection is carried? out. Zellos (1962), reporting from Edinburgh, $\omega$ stated that lobectomy is probably the smallest? resection permissible if an adequate tumouro operation is to be undertaken. Because of the variable behaviour of the tumour we think this ${ }^{-}$ view is correct, and that lobectomy should be performed whenever possible. Closure of a lower lobe stump when an extended excision of the? lower lobe bronchus has compromised the patency of the upper lobe has been carried out in three patients with carcinoma, using a circular patch of 
T A B L E

\begin{tabular}{|c|c|c|c|c|c|c|c|c|c|c|c|c|}
\hline \multirow{2}{*}{ Patient } & \multirow{2}{*}{$\begin{array}{c}\text { Age at } \\
\text { Opera- } \\
\text { tion }\end{array}$} & \multirow{2}{*}{ Sex } & \multicolumn{2}{|c|}{$\begin{array}{l}\text { Infiltration at } \\
\text { Operation }\end{array}$} & \multicolumn{2}{|c|}{$\begin{array}{l}\text { Lymph Node } \\
\text { Involvement }\end{array}$} & \multirow{2}{*}{$\begin{array}{c}\text { Palp- } \\
\text { able at } \\
\text { Opera- } \\
\text { tion }\end{array}$} & \multicolumn{2}{|c|}{ Pathologist } & \multirow{2}{*}{ Operation } & \multirow{2}{*}{ Date } & \multirow{2}{*}{ Result } \\
\hline & & & $\begin{array}{l}\text { Macro- } \\
\text { scopic }\end{array}$ & $\begin{array}{l}\text { Micro- } \\
\text { scopic }\end{array}$ & $\begin{array}{l}\text { At Op- } \\
\text { eration }\end{array}$ & $\begin{array}{l}\text { Micro- } \\
\text { scopic }\end{array}$ & & $\mathbf{A}$ & $\mathbf{B}$ & & & \\
\hline 1 & 41 & $\mathbf{M}$ & Yes & Yes & 一 & - & Yes & Regular & Irregular & $\begin{array}{l}\text { Right pneumon- } \\
\text { ectomy }\end{array}$ & 1951 & $\begin{array}{l}1961 \text { Developed skin sec- } \\
\text { ondary and carcinoid } \\
\text { syndrome } \\
1963 \text { Died. P.M. deposits } \\
\text { in left lung, liver, me- } \\
\text { sentery, pancreas, left } \\
\text { kidney, right supra- } \\
\text { renal }\end{array}$ \\
\hline 2 & 60 & $\mathbf{M}$ & No & Yes & No & No & Yes & Irregular & - & $\begin{array}{l}\text { Left pneumonec- } \\
\text { tomy }\end{array}$ & 1953 & 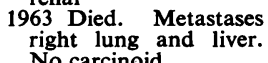 \\
\hline 3 & 25 & $\mathbf{M}$ & Yes & Yes & No & No & Yes & Regular & Regular & Right middle lo- & 1955 & Alive, no recurrence \\
\hline 4 & 21 & $\mathbf{M}$ & No & Yes & No & Yes & Yes & Regular & Regular & Left lower lob- & 1956 & Alive, no recurrence \\
\hline 5 & 18 & $\mathbf{F}$ & Yes & Yes & No & No & Yes & Irregular & $\begin{array}{l}\text { Malignant } \\
\text { but not } \\
\text { carcin- } \\
\text { oid }\end{array}$ & $\begin{array}{l}\text { ectomy } \\
\text { Right middle lo- } \\
\text { bectomy }\end{array}$ & 1956 & $\begin{array}{l}1957 \text { Died. Metastases in } \\
\text { both lungs }\end{array}$ \\
\hline 6 & 49 & $\mathbf{F}$ & No & Yes & No & No & No & Regular & Regular & Right lower lob- & 1957 & Alive, no recurrence \\
\hline 7 & 50 & $\mathbf{M}$ & No & Yes & No & No & Yes & & Regular & Right upper lob- & 1958 & Alive, no recurrence \\
\hline 8 & 49 & $\mathbf{F}$ & No & Yes & No & No & No & Regular & Regular & Left upper lob- & 1958 & Alive, no recurrence \\
\hline 9 & 63 & $\mathbf{M}$ & No & Yes & No & No & No & Regular & $\begin{array}{l}\text { Oat-cell } \\
\text { carcin- }\end{array}$ & $\begin{array}{l}\text { ectomy } \\
\text { Left upper lob- } \\
\text { ectomy }\end{array}$ & 1959 & Alive, no recurrence \\
\hline 10 & 38 & $\mathbf{F}$ & No & No & No & No & Yes & Regular & Regular & $\begin{array}{l}\text { Local removal } \\
\text { by thoraco- } \\
\text { tomy and }\end{array}$ & 1959 & $\begin{array}{l}1967 \text { Right lower lobec- } \\
\text { tomy for symptomless } \\
\text { local recurrence }\end{array}$ \\
\hline 12 & 62 & $\mathbf{M}$ & Yes & Yes & Yes & Yes & Yes & $\begin{array}{l}\text { Irregular } \\
\text { Regular }\end{array}$ & Irregular & $\begin{array}{l}\text { Right pneumon- } \\
\text { ectomy }\end{array}$ & 1963 & $\begin{array}{l}\text { Died } 4 \text { months after op- } \\
\text { eration } \\
\text { Metastasis in liver; no } \\
\text { carcinoid } \\
\text { Alive and well }\end{array}$ \\
\hline 13 & 58 & $\mathbf{F}$ & Yes & Yes & Yes & Yes & Yes & Irregular & Irregular & $\begin{array}{l}\text { Left pneumonec- } \\
\text { tomy }\end{array}$ & 1963 & $\begin{array}{l}\text { Post-operative death. } \\
\text { P.m. no tumour else- } \\
\text { where. Cerebral infarct }\end{array}$ \\
\hline 14 & 57 & $\mathbf{M}$ & Yes & Yes & Yes & No & Yes & Irregular & Regular & Right pneumon- & 1963 & Alive, no recurrence \\
\hline 15 & 21 & $\mathbf{F}$ & Infiltr & $\begin{array}{l}\text { ation of } \\
\text { broncl }\end{array}$ & fronc & hial wal & at & Irregular & Regular & ectomy & 1964 & $\begin{array}{l}\text { Died } 3 \text { months after diag- } \\
\text { nosis. Metastases in }\end{array}$ \\
\hline 16 & 32 & $\mathbf{M}$ & Yes & Yes & No & Yes & No & Regular & Regular & $\begin{array}{l}\text { Left upper lob- } \\
\text { ectomy }\end{array}$ & 1965 & $\begin{array}{l}\text { Alive and well } \\
\text { loth lungs and orain }\end{array}$ \\
\hline
\end{tabular}

teflon. The long-term result has been satisfactory in each patient. The use of this technique is recommended as an alternative to pneumonectomy when the endobronchial tumour is unusually close to the upper lobe and routine closure of the lower lobe stump is impossible.

What differences there were in interpretation of the histopathology between pathologists $A$ and $B$ are set out in the Table. Patients 9 and 15 are of most interest. Different opinions were expressed on the histology in patient 9. The occasional difficulty in distinguishing histologically between a carcinoid and an oat-cell carcinoma is recorded (Gowenlock, Platt, Campbell, and Wormsley, 1964). The tumour in patient 15 , a 21-year-old lady, had already metastasized at the time of diagnosis. Pathologist B, unaware of any clinical detail, regarded the tumour as a regular carcinoid. From patient 9 it must be concluded that an endobronchial tumour, non-invasive and impalpable at operation, may be an oat-cell carcinoma histologically, and from patient 15 that a carcinoid tumour of regular histology may metastasize. Markel et al. (1964) stated 'we could discern no cytological features that would indicate which tumours had metastasized or subsequently could do so', whereas McBurney et al. (1953) considered that in those tumours that metastasized distally the carcinoid pattern was not orderly. Patient 5 emphasizes the difficulty in deciding the longterm course of the tumour solely on the histopathology. The patient, a girl of 18, had a tumour infiltrating the wall of the middle lobe bronchus ; invasion of the middle lobe bronchus was visible at operation; a haemothorax believed to be traumatic was present. The nature of this tumour aroused interest; the tumour was submitted to the Tumour Registry of the British Association of 
Thoracic Surgeons and six different opinions on the histology were obtained, ranging from a bronchial adenoma to an adenocarcinoma. In view of these contrary opinions it is uncertain what priority the histological appearance should be given in assessing the long-term course, although the possibility of recurrence is immediately manifest once the suspicion of overt malignancy is reported at microscopy.

\section{DISCUSSION}

At every phase the object of the study was to assess potential malignancy by any method additional to the histological appearance. To be of value, the significance of these methods of assessment must be available to the surgeon at the time the operation is performed, to decide on the extent of resection. Their value is diminished if they are the only means of deciding prognosis after operation when a full examination of the surgical specimen is made too late in time to influence the nature and extent of surgery. Any feature of the tumour considered in isolation can be regarded as no more than a pointer to its probable natural history.

FACTORS SUGGESTING LONG-TERM BENIGN COURSE For descriptive purposes the histological appearances of the tumours are arbitrarily divided inţo the 'regular', where the cell arrangement is entirely orderly and typical, and the 'irregular', where, because of pleomorphism, unusual arrangement or occasional abnormal mitosis, malignant potential exists. Baldwin and Grimes (1967) defined and illustrated two types of tumour which they described as the benign and the malignant carcinoid. The factors discussed below are arranged in clinical sequence rather than in priority of importance.

Long previous history Provided the tumour has remained entirely endobronchial, a long history suggests a benign lesion. In one patient the presence of a left main bronchus tumour eight years prior to bronchoscopy was suspected, on the grounds of increasing radiological collapse. The tumour was removed by bronchotomy. Left pneumonectomy was carried out some months later, because of extensive bronchiectasis from tumour obstruction. No trace of residual tumour was detected on microscopy. The patient died 10 years later from cor pulmonale. No trace of tumour was found at necropsy ; the tumour was a 'regular' carcinoid. The history of this patient demonstrated that a tumour may remain endobronchial for many years. Fraser (1957) described total removal by bronchoscopy. His patient sub- $\frac{\bar{\sigma}}{\bar{D}}$ sequently underwent lobectomy. Total removal of $\vec{\nabla}$ the tumour by the original bronchoscopy was $\varrho$ confirmed.

Characteristic bronchoscopy appearance $\mathrm{A}$ freely mobile endobronchial tumour suggests $\vec{\sigma}$ absence of penetration of the bronchial wall, $\stackrel{\curvearrowright}{\vec{*}}$ generally a favourable feature. A raspberry red tumour, free from evidence of necrosis, is more $A$ likely to be benign than the endobronchial car- $\overrightarrow{.}$ cinoma which commonly is necrotic and resembles $\omega$ a plug of wet cotton wool within the bronchial 음 lumen. The biopsy at the time of pre-operative bronchoscopy may be misleading. Zellos (1962) reported this in seven out of 40 patients.

Characteristic bronchogram appearance $\mathrm{A} \vec{\oplus}$ smooth, hemispherical filling defect in the bronchogram is characteristic of a 'regular' carcinoid. Three examples are shown (Figs 1 to 3). Six patients with such a defect show no recurrence, although one (case 4, Table) had hilar lymph node involvement associated with a histo- $\stackrel{\circ}{\varnothing}$ logically 'regular' carcinoid removed in 1956. We $\varrho$ believe the bronchogram to be a useful pre-opera- $\overrightarrow{\overrightarrow{0}}$ tive method of excluding gross invasion of the 3 bronchial wall.

Absence of the carcinoid syndrome This is a constant feature of the operable carcinoid. We have not recognized an example of the carcinoid syndrome in a patient at the time of surgical treatment. A significant early report is that of Kincaid-Smith and Brossy (1956), who described the symptom of persistent watery diarrhoea in a patient six years after lobectomy for carcinoid. Metastases were present in the bowel at lapar- $\frac{D}{0}$ otomy. The syndrome was not observed in 46 . patients treated surgically by Markel et al. (1964), N although one patient subsequently developed the $N$ carcinoid syndrome after operation. Baldwin and $\mathcal{N}$ Grimes (1967) remarked on the rarity of bron- $\omega$ chial adenoma with the carcinoid syndrome; it 2 was not observed in their 56 patients treated surgically. Zellos (1962) reported one patient from $\mathbb{D}$ 33 who developed the syndrome three years after operation. It was not reported in any case pre- $\frac{0}{3}$ operatively. Our patient (case 1, Table) devel- $\frac{\stackrel{D}{\mathbb{D}}}{\mathrm{O}}$ oped the syndrome 10 years after pneumonectomy. $\frac{\rho}{\mathbb{Q}}$ Multiple skin nodules were the first evidence of $\stackrel{\mathbb{Q}}{\varrho}$ recurrence. McBurney et al. (1953) stated that it $\overline{0}$ was evident that a patient may live for several 8 

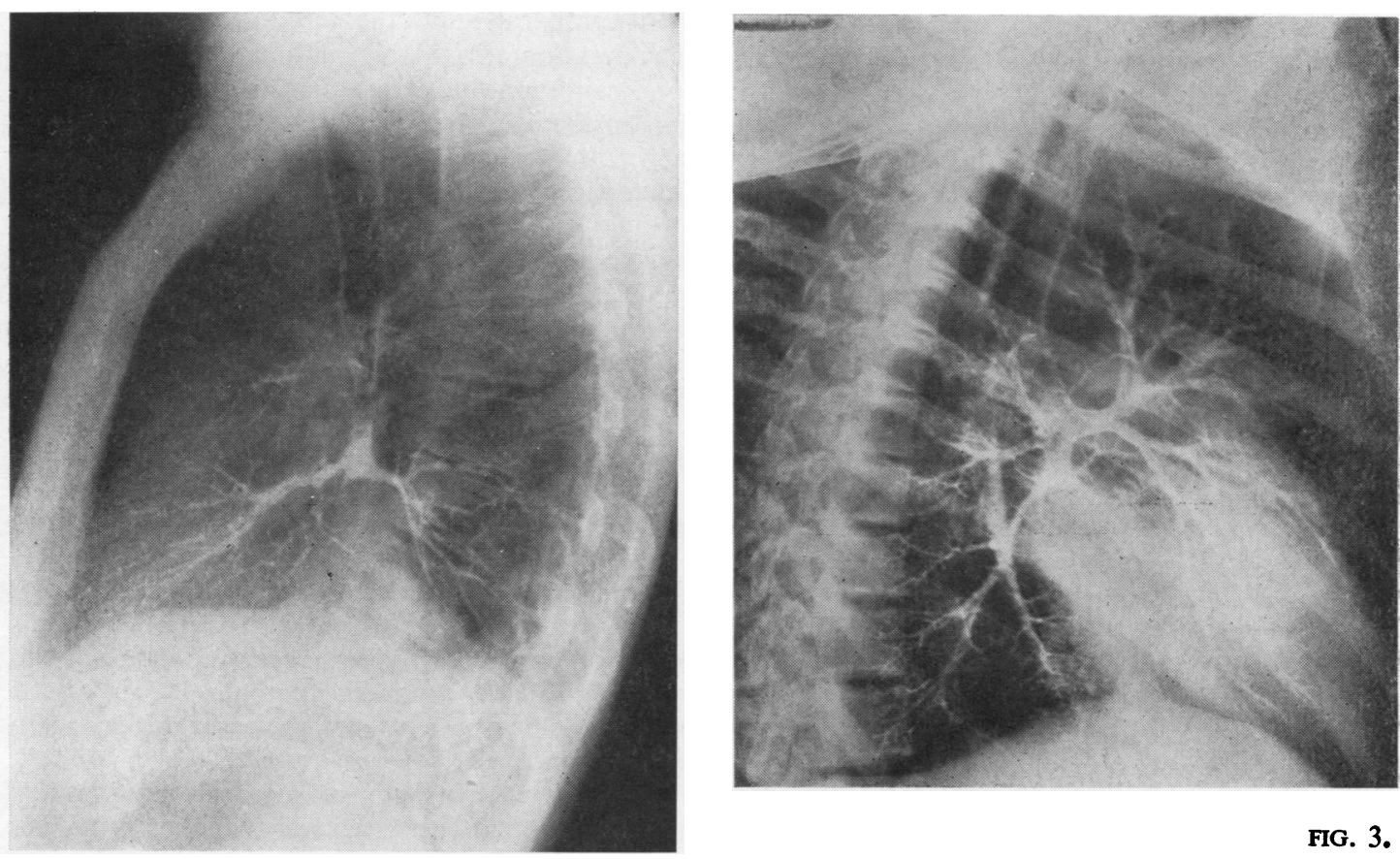

FIG. 3.

FIG. 1 .

FIG. 1. Endobronchial carcinoid blocking basal segments of right lower lobe. The hemispherical filling defect and the absence of rattailing of the bronchus is characteristic of a non-invasive tumour. Female aged 56.

FIG. 2. Endobronchial carcinoid blocking basal segments of left lower lobe. Female aged 40.

FIG. 3. Endobronchial carcinoid blocking basal segments of left lower lobe. Male aged 23.

FIG. 2. 
years even with definite distant metastatic disease. Maier (1963) reported lobectomy for carcinoid in a patient in 1947. In 1956 the patient developed the carcinoid syndrome and laparotomy confirmed liver metastases. At the time of the report in 1963 her condition had remained unchanged since 1956. Local chest recurrence was not demonstrated. Askergren and Hillenius (1964) reported the syndrome developing eight years after lobectomy for carcinoid. Numerous recent reports associate bronchial carcinoid and liver metastases with the carcinoid syndrome. The syndrome has been described with metastases elsewhere than in the liver (Joseph and Taylor, 1960). A search should be made for evidence of the syndrome in all patients with bronchial carcinoid; positive evidence may be assumed to confirm the presence of metastases. Operation as a curative measure in these circumstances is not possible. As a palliative measure surgery has a place; Brindley and Bonnet (1967), referring to lung carcinoid and hepatic metastases, stated 'even when all lesions cannot be removed, decreasing the total tumour mass will effect significant clinical improvement'. These authors also mentioned increased sensitivity to anaesthetic agents in patients who had the carcinoid syndrome; they warned against the treatment of hypotension during operation, with vasopressor agents.

Raised levels of serotonin in the blood and 5 hydroxyindoleacetic acid in the urine may exist without the carcinoid syndrome (Warner, Kirschner, and Warner, 1961). These raised levels may have a different significance from the point of view of surgical treatment than the fully developed carcinoid syndrome. Kirschner (1963) later reported reversion to normal or near normal levels more than two years after surgery in the two patients described in the original paper (Warner, et al., 1961). No evidence of tumour recurrence was noted during this interval.

Impalpability of the tumour at operation Our previously held view that a tumour which is impalpable at operation can always be regarded as benign is not correct. A tumour which at bronchoscopy appears to fill the bronchus may be impalpable at operation. We have noted this in five patients $(6,8,9,12$, and 16). These five are well and free of recurrence. Pathologist $B$ regarded one impalpable tumour as an oat-cell carcinoma (case 9). This impalpable tumour was considered endobronchial at operation but invasion of the bronchial wall was noted at microscopy. Lobectomy was performed and the patient is well and free of recurrence nine years after operation.
In another patient the tumour was impalpable at operation (case 16) although a roughened appearance of the external wall of the bronchus suggested invasion which was confirmed at microscopy. Impalpability at operation cannot confirm either a regular histological appearance or absence \& of invasion of the bronchial wall. Nevertheless, we $\vec{\circ}$ believe that impalpability and long survival are related.

Absence of invasion of bronchial wall If the $\overrightarrow{\vec{x}}$ tumour is entirely endobronchial, that is to say, i confined to the bronchial mucosa, the outlook is good. The Table confirms that where there is $\vec{\omega}$ evidence at operation of invasion of the bronchial wall, that is to say, where there is gross evidence of bronchial wall invasion, the outlook is poor. $\vec{c}$ The Table also shows the frequency of microscopic invasion of the bronchial wall in patients thought from the appearances at operation to have wholly endobronchial tumours. It can also be $\vec{\emptyset}$ noted that five patients with microscopic invasion of only all survived 10 years (cases $2,4,6,7$, and 8 ), and four are alive and free of recurrence. There is evidence that gross invasion of the bronchial wall, detectable by the surgeon at operation, carries a poor prognosis, whereas microscopic invasion is compatible with long-term survival. It is for this reason that we consider the 'iceberg' adenoma as a carcinoma, regardless of the histology. On occasions, widespread early dissemination may occur, suggesting something more than low-grade malignancy (patients 5 and 15). Generally we have had no difficulty in deciding at operation that extra bronchial spread existed, though the problem is complicated by the fact that distension of the bronchial wall may be present to a marked degree without actual invasion. Fraser (1957) noted that tumour growth may displace and compress lung tissue, giving the appearance of a false capsule to the tumour.

Involvement of hilar lymph nodes Deposits of $N$ carcinoid tumour may be found in hilar lymph nodes by direct extension of the tumour or by $N$ lymphatic permeation. Positive lymph nodes in $\omega$ association with an apparently benign tumour is one of the more perplexing features of this lesion.

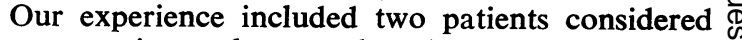
at operation to have no lymph node involvement. At microscopy involvement was found to be 0 present in each patient; in only one of 10 nodes $\stackrel{\overrightarrow{\mathbb{D}}}{\overrightarrow{\mathrm{C}}}$ sectioned in patient 16 (Table). It would seem $\stackrel{\bigcirc}{\overparen{D}}$ important that as many apparently normal nodes $\stackrel{\mathbb{2}}{\varrho}$ as possible should be removed and sectioned if $\bar{Q}$ involvement is to be observed as frequently as it 
actually exists. The surprise finding of involved nodes in these two patients (4 and 16) was associated with a 'regular' histology in each patient. Both are alive, one more than 12 years after lobectomy. McBurney et al. (1953) reported two cases with a perfectly regular carcinoid pattern and little or no pleomorphism or abnormal mitotic figures, who had local lymph node involvement. Zellos (1962) described hilar lymph node involvement in 10 out of 33 carcinoid tumours. Markel et al. (1964) reported involvement in nine out of 58 patients. One of these patients died 17 years after resection; necropsy revealed no residual tumour throughout the body. In Wilkins et al. (1963) series, one patient is reported alive and well 26 years after lobectomy. Two positive nodes were present at the time of operation. Gross lymph node involvement, obvious at operation and confirmed at microscopy, is a bad prognostic sign. Isolated microscopic involvement of apparently normal nodes is clearly compatible with long-term survival. The exact significance of this microscopic finding is uncertain, and the natural history of an unoperated tumour of this category is inevitably unknown.

In one patient (No. 14) lymph node involvement was considered as definite at operation. Pneumonectomy with removal of the gland field was carried out. Microscopy of the nodes showed no evidence of involvement of any hilar lymph nodes by tumour. Recognition at operation that lymph nodes are involved must be accepted as unreliable.

\section{CONCLUSION}

From a limited experience of the carcinoid tumour we believe that it is impossible on any single feature, such as the histopathology, to offer a reliable prognosis. We appreciate that there is no need to be committed to a prognosis solely on the histopathology. It is likely that the result of a bronchial biopsy will be the first and possibly most important factor pointing to the true nature of the tumour and, therefore, to its proper treatment.

The following features suggest that lobectomy should be carried out in all patients: (1) the uncertain behaviour of some of these tumours; (2) the occasional unreliability of the pre-operative bronchial biopsy ; (3) the lack of uniformity of histological interpretation; (4) the frequent absence of correlation between the surgeon's assessment of bronchial wall invasion and hilar lymph node involvement with the evidence pro- vided later by the subsequent microscopic examination of the surgical specimen; (5) local recurrence may occur years after apparently successful local removal and may be symptomless. If recurrence is in a main bronchus, the radiographic appearances may be non-contributory ; and (6) the occasional occurrence of irreversible bronchiectasis in the lobe distal to the bronchial block, which may be difficult to confirm before or at the time of operation.

The lobectomy should be combined in all patients with removal of the maximum possible number of hilar lymph nodes: there may be exceptions to this. Establishment of an airway in an elderly patient with poor respiratory reserve can be satisfactorily achieved by bronchoscopic removal, sometimes with survival for many years. A long-pedicled, intrabronchial tumour is not always a carcinoid tumour. For the patient in the wage-earning group, when the condition allows a choice of operation to be made, we would now never remove a carcinoid tumour locally by bronchotomy or by bronchoscopy; we would carry out pneumonectomy only in the exceptional circumstance of being unable to remove all macroscopic tumour by any other operation. Lobectomy with an adequate margin of tumour-free bronchus, combined with as complete a hilar lymph node clearance as possible, is the operation of choice.

I am most grateful to Professor Donald Heath for his help in so willingly examining a large number of slides. Also to Dr. A. P. Prior, Dr. D. F. Barrowcliff, and Dr. M. K. Alexander, of the Central Pathological Laboratory, Warwick, for their continued interest; this study has depended to a great extent on their data. Mr. Ronald Belsey kindly allowed me access to his case notes of one patient.

\section{REFERENCES}

Askergren, A., and Hillenius, L. (1964). Bronchial adenomas and the carcinoid syndrome. Acta med. scand., 175, 43.

Baldwin, J. N., and Grimes, O. F. (1967). Bronchial adenomas. Surg. Gynec. Obstet., 124, 813 .

Borggreve, J. R. (1966). A bronchial adenoma of 33 years standing (in Dutch; English summary). Ned. T. Geneesk, 110, 1532.

Brindley, G. V., and Bonnet, J. D. (1967). Bronchial adenoma and the carcinoid syndrome. Ann. Surg., 165, 670.

d'Abreu, A. L. (1958). A Practice of Thoracic Surgery, 2nd ed., p. 283. Edward Arnold, London.

Edmunds, L. H. (1966). In discussion of Wilkins, E. W., Edmunds, L. H., and Castleman, B. (1966). Cases of thymoma at the Massachusetts General Hospital. J. thorac. cardiovasc. Surg., 52 322.

Fraser, K. (1957). Bronchial adenoma. Brit. J. Surg., 44, 570.

Gowenlock, A. H., Platt, D. S., Campbell, A. C. P., and Wormsley, K. G. (1964). Oat-cell carcinoma of the bronchus secreting 5-hydroxytryptophan. Lancet, 1, 304.

Joseph, M., and Taylor, R. R. (1960). Argentaffinoma of the lung with carcinoid syndrome. Brit. med. J., 2, 568 .

Kincaid-Smith, P., and Brossy, J-J. (1956). A case of bronchial adenoma with liver metastasis. Thorax, 11, 36. 
Kirschner, P. A. (1963). In discussion of Wilkins, E. W., Darling, R. C., Soutter, L., and Sniffen, R. C. (1963). A continuing clinical survey of adenomas of the trachea and bronchus in a general hospital. J. thorac. cardiovasc. Surg., 46, 279.

Maier, H. C. (1963). In discussion of Wilkins, E. W., Darling, R. C., Soutter, L., and Sniffen, R. C. (1963). A continuing clinical survey of adenomas of the trachea and bronchus in a general hospital. Ibid., 46, 279.

Markel, S. F., Abell, M. R., Haight, C., and French, A. J. (1964). Neoplasms of bronchus commonly designated as adenomas. Cancer (Philad.), 17, 590.

McBurney, R. P., Kirklin, J. W., and Woolner, L. B. (1953). Metastastizing bronchial adenomas. Surg. Gyncc. Obstet., 96, 482.

Moersch, H. J., and McDonald, J. R. (1950). Bronchial adenoma. J. Amer. med. Ass., 142, 299.
Price Thomas, C. (1954). Benign tumours of the lung. Lancet, 1, 1. (1956). Conservative resection of the bronchial tree. J. roy. Coll. Surg. Edinb., 1, 169.

Thompson, V. C. (1965). In Clinical Surgery, ed. Rob, C., and Smith, R., vol. 5: Thorax, ed. d'Abreu, A. L., p. 184. Butterworths, London.

Warner, R. R. P., Kirschner, P. A., and Warner, G. M. (1961). Serotonin production by bronchial adenomas without the car- O cinoid syndrome. J. Amer. med. Ass., 178, 1175 .

Wilkins, E. W., Darling, R. C., Soutter, L., and Sniffen, R. C. (1963). A continuing clinical survey of adenomas of the trachea and bronchus in a general hospital. J. thorac. cardiovasc. Surg., 46, 279.

Willis, R. A. (1960). Pathology of Tumours, 3rd ed., p. 383. Butterworths, London.

Zellos, S. (1962). Bronchial adenoma. Thorax, 17, 61. 